\title{
PERAN KELOMPOK NELAYAN “GULAMAH” TERHADAP PENGEMBANGAN BUDIDAYA KERANG HIJAU (Perna viridis) DI KAWASAN PESISIR KOTA TEGAL
}

\author{
Narto, Sutaman, Sri Mulatsih dan Suyono \\ Program Studi Budidaya Perairan Fakultas Perikanan dan Ilmu Kelautan \\ Universitas Pancasakti Tegal
}

\begin{abstract}
ABSTRAK
Kegiatan pembangunan di kawasan pesisir Kota Tegal tidak terlepas dari daya dukung lingkungan dan sumberdaya alam. Kegiatan ini dilakukan secara terpadu oleh berbagai pihak terkait dengan tujuan meningkatkan kesejahteraan masyarakat setempat. Potensi-potensi yang dapat dikembangkan antara lain potensi sumberdaya alam dan sumberdaya manusia melalui kegiatan pengembangan budidaya kerang hijau (Perna viridis) yang dilakukan oleh kelompok nelayan "gulamah" sebagai sumber pendapatan alternatif. Penelitian ini bertujuan untuk mengkaji tingkat pengetahuan dan respon kelompok nelayan "gulamah" terhadap kegiatan pengembangan budidaya kerang hijau di kawasan pesisir Kota Tegal. Hasil analisis menunjukkan bahwa pemerintah Kota Tegal dan lembaga pendidikan tinggi yang ada di Wilayah Pesisir Kota Tegal cukup berperan dalam proses pengembangan budidaya kerang hijau. Kelompok nelayan "Gulamah" merupakan pihak yang sangat berperan dalam upaya pengembangan budidaya kerang hijau terutama dalam peningkatkan kualitas SDM berbasis pengetahuan, pemasaran, penyediaan sarana dan prasarana kegiatan budidaya.
\end{abstract}

KataKunci: Kelompok nelayan, budidaya kerang hijau, pengembangan potensi.

\begin{abstract}
Development activities in the coastal area of Tegal City can not be separated from the carrying capacity of the environment and natural resources. This activity is conducted in an integrated manner by various parties related to the purpose of improving the welfare of the local community. Potentials that can be developed include the potential of natural resources and human resources through the development of green shellfish cultivation (Perna viridis) conducted by the group of fishermen "gulamah" as an alternative source of income. The objective of this research was to study the level of knowledge and response of fishermen group "gulamah" to the development activities of shellfish cultivation in the coastal area of Tegal City. The results of the analysis show that the Tegal City government and the higher education institutions in the Coastal Areas of Tegal City have a enough significant role in the cultivation development process of green shells. Fishermen group "Gulamah" is a high significant role in the development of green shellfish cultivation, especially in improving the quality of human resources based on knowledge, marketing, providing facilities and infrastructure of cultivation activities
\end{abstract}

Keywords: Fishermens group, cultivation of mussel, potential development. 


\section{PENDAHULUAN}

Kegiatan pembangunan di kawasan pesisir Kota Tegal tidak terlepas dari daya dukung lingkungan, keberlangsungan sumberdaya alam dan dilakukan secara terpadu oleh berbagai pihak terkait dengan menekankan peningkatan kesejahteraan masyarakat setempat, Kelompok nelayan di wilayah pesisir Kota Tegal mempunyai potensi-potensi yang dapat dikembangkan antara lain potensi sumberdaya a $1 \mathrm{am}$ d a n sumberdaya manusia melalui kegiatan budidaya kerang hijau (Perna viridis) yang dilakukan oleh kelompok nelayan sebagai sumber pendapatan alternatif, sehingga peran kelompok nelayan "gulamah" terhadap pengembangan budidaya kerang hijau di wilayah Pesisir Kota Tegal menjadi hal yang penting dalam memberikan informasi potensi pesisir dan lautan yang terpadu (Rais, J.et al, 2004).

\section{Kerang hijau (Perna viridis)} merupakan salah satu sumberdaya yang memiliki potensi tinggi di Indonesia (Gang.C,et al.1998). Dalam rangka terus meningkatkan produksi budidaya laut yang hingga saat ini masih ketinggalan dibandingkan dengan budidaya air payau maupun air tawar, maka perlu dilakukan peningkatan peran kelompok nelayan dalam pengembangan potensi budidaya kerang hijau (Perna viridis) sebagai sumber pendapatan alternatif sehingga mampu meningkatkat kesejahteraan kelompok nelayan di kawasan pesisir Kota Tegal.

Tujuan dari penelitian ini adalah untuk mengkaji tingkat pengetahuan dan respon kelompok nelayan "gulamah" terhadap kegiatan budidaya kerang hijau (Perna viridis) di kawasan pesisir Kota Tegal. Salah satu wilayah pesisir yang memiliki potensi tersebut yaitu Kota Tegal, dengan panjang garis pantai $7,5 \mathrm{~km}$ dan luas lautannya sebesar $216,00 \mathrm{~km}^{2}$.

Kota Tegal merupakan salah satu kota yang ada di wilayah pantura Jawa Tengah. Letak secara geografis Kota Tegal pada $109^{\circ} 08^{\prime}-109^{\circ} 10^{\prime} \mathrm{BT}$ \& $6^{\circ} 50^{\prime}-6^{\circ} 53^{\prime} \mathrm{LS}$. (BPS Kota Tegal, 2016). Sedangkan secara administrasi Kota Tegal memiliki batas wilayah sebagai berikut:

1. Bagian utara berbatasan langsung dengan Laut Jawa.

2. Bagian timur berbatasan dengan Kabupaten Tegal.

3. Bagian selatan berbatasan dengan Kabupaten Tegal.

4. Bagian barat berbatasan dengan Kabupaten Brebes

Posisi geografis dan batas-batas wilayah Kota Tegal secara rinci dapat disajikan pada gambar 1 berikut : 


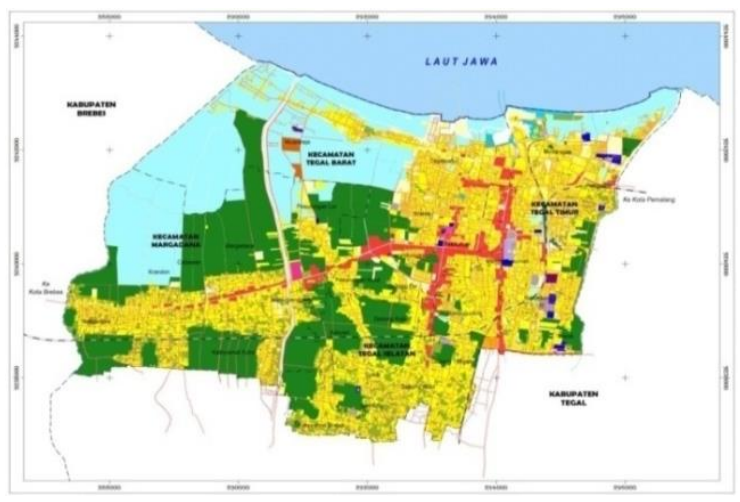

Gambar 1. Peta Pemanfaatan Ruang Kota Tegal Sumber : Bappeda Kota Tegal (2015)

\section{METODE PENELITIAN}

Penelitian ini menggunakan studi kasus. Pengambilan data dilakukan dengan beberapa metode, meliputi: survei langsung dan wawancara, melalui teknik penarikan data dengan mengambil seluruh anggota kelompok nelayan sebagai responden (Sugiyono,2006)

Penelitian ini dilaksanakan di Wilayah Pesisir Kota Tegal yang berlokasi Kelompok Nelayan "Gulamah" Kelurahan Panggung Kecamatan Tegal Timur Kota Tegal, dari Bulan Januari hingga Agustus 2017. Data yang digunakan adalah data primer dan data sekunder. Data primer diperoleh dari wawancara dan observasi yang terencana (pedoman kuesioner). Observasi dimaksudkan untuk memperoleh gambaran tentang lokasi penelitian dengan teknik pengambilan sampling responden berdasarkan purposive sampling, data sekunder adalah data dan peta yang diperoleh dari berbagai instansi/lembaga baik pemerintah maupun swasta.

Analisa data yang dilakukan dengan metode deskriptif kualitatif dan deskripsi kuantitatif. Sugiono (2006) menyatakan bahwa analisa deskriptif kualitatif adalah pengolahan data yang dilakukan melalui beberapa pertimbangan logika dengan bahasa penulis yang sistematis, sedangkan analisa data kuantitatif merupakan pengolahan data dengan mengunakan perhitungan matematis sederhana seperti penjumlahan, persentase, angka rata-rata dan sebagainya .

Sugiyono (2006) menyatakan penilaian secara kuantitatif terhadap peran kelompok nelayan dilakukan dengan metode skoring dan pembobotan. Skala Likert digunakan untuk mengukur sikap, pendapat dan persepsi seseorang atau sekelompok orang tentang fenomena sosial. Dengan skala ini, variabel yang akan diukur dijabarkan menjadi indikator variabel. Kemudian indikator tersebut dijadikan sebagai titik tolak untuk menyusun itemitem instrumen yang dapat berupa pertanyaan atau pernyataan. Jawaban setiap item mempunyai gradasi dari sangat positif sampai sangat negatif, yang dapat berupa kata-kata sebagai contoh antara lain sangat berperan, berperan, cukup berperan, tidak terlalu berperan dan sangat tidak berperan. 
Untuk penilaian peran kelompok nelayan terhadap kegiatan budidaya kerang hijau (Perna viridis), maka jawaban itu dapat diberi skor, misalnya:
a. Sangat Berperan
b. Berperan
c. Cukup Berperan
d. Tidak Terlalu Berperan
e. Sangat Tidak Berperan

Instrumen ini dapat dibuat dalam bentuk checklist ataupun pilihan ganda. Data yang telah dianalisa dengan skala Likert kemudian dihitung korelasi antara setiap pernyataan dengan skor total dengan menggunakan rumus korelasi Product Moment yaitu teknik korelasi tunggal yang digunakan untuk mencari koefisien korelasi antara data interval satu dengan lainnya.

\section{HASIL DAN PEMBAHASAN}

\section{Peran Kelembagaan Dalam Kegiatan Budidaya Kerang Hijau (Perna viridis)}

\section{Pemerintah Kota}

Mengacu pada PERDA Provinsi Jawa Tengah No 04 Tahun 2014 tentang Rencana Zonase wilayah pesisir dan pulau pulau kecil dalam pasal 14, point $\mathrm{d}$ : meningkatkan nilai sosial, budaya, dan ekonomi masyarakat melalui peran serta masyarakat dalam pemanfaatan sumber daya pesisir dan pulau-pulau kecil.
Hasil penelitian dimana peran serta pemerintah daerah terhadap pengembangan budidaya kerang hijaudapat dilihat pada tabel 1 berikut ini.

Tabel 1. Peran Pemerintah Kota dalam Kegiatan Budidaya Kerang Hjau (Perna viridis)

\begin{tabular}{ccccc}
\hline No & $\begin{array}{c}\text { Peran } \\
\text { Pemerintah } \\
\text { Kota }\end{array}$ & Skor & $\begin{array}{c}\text { Jumlah } \\
\text { Responden }\end{array}$ & $\begin{array}{c}\text { Prosentase } \\
\%\end{array}$ \\
\hline 1 & $\begin{array}{c}\text { Sangat } \\
\text { Berperan }\end{array}$ & 5 & 3 & 8,57 \\
\hline 2 & Berperan & 4 & 2 & 5,73 \\
\hline 3 & $\begin{array}{c}\text { Cukup } \\
\text { Berperan }\end{array}$ & 3 & 18 & 51,42 \\
\hline 4 & $\begin{array}{c}\text { Tidak } \\
\text { Terlalu } \\
\text { Berperan } \\
\text { Tidak }\end{array}$ & 2 & 12 & 34,28 \\
\hline 5 & $\begin{array}{c}\text { Berperan } \\
\text { Total }\end{array}$ & 0 & 0 \\
\hline
\end{tabular}

Sumber : Hasil Penelitian (2017)

Dalam Tabel di atas menunjukan hal bahwa perhatian pemerintah kota masih cukup berperan dalam pengembangan budidaya kerang hijau, dimana sebesar $51,42 \%$ menyatakan bahwa pemerintah kota cukup berperan. Pada jawaban no 3 (tiga) dimana menurut masyarakat, pemerintah hanya Berperan sebesar $34,28 \%$.

Berdasarkan hasil analisis teknik korelasi Product Moment didapat hasil 0,418 (pernyataan 1), jika dibandingkan dengan angka kritik tabel korelasi nilai -r maka pernyataan ini memiliki validitas konstruk, artinya pernyataan ini memiliki hubungan korelasi dengan pernyataan yang lain. 
Hasil penelitian di lapangan, kelompok nelayan "gulamah" mengeluhkan keterlibatan pemerintahkota dalam hal pengembangan potensi budidaya kerang hijau (Perna viridis) Selama ini pemerintah kota hanya sering terlibat. Sementara itu, kelompok nelayan "gulamah" yang menjadi pelaku usaha dalam hal pengelolaan dan pemanfaatan budidaya kerang hijau

\section{Kelompok Nelayan}

Dalam pengembangan budidaya kerang hijau di wilayah Pesisir Kota Tegal tidak terlepas juga dari peran kelompok nelayan yang ada di sana. Kelompok nelayan "gulamah" selalu melibatkan diri dalam usaha budidaya kerang hijau. Kelompok ini juga rutin melakukan kegiatan teknis budidaya dari persiapan,monitoring maupun cara pemanenan yang dilakukan tiap satu bulan sekali, ada juga yang melakukan tiap du minggu sekali. Peran kelompok nelayan tersaji dalam Tabel 2.

Kelompok nelayan menilai peran anggota kelompok berperan dalam pengembangan budidaya kerang hijau (49\%), dan hanya 3 responden saja yang memberi jawaban bahwa kelompok nelayan tidak terlalu berperan.

Berdasarkan hasil analisis korelasi Product Moment didapat hasil 0,724 (pernyataan 3), jika dibandingkan dengan angka kritik tabel korelasi nilai -r maka pernyataan ini memiliki validitas konstruk, artinya memiliki hubungan korelasi dengan pernya-taan yang lain.

Tabel 2. Peran kelompok nelayan dalam Kegiatan Budidaya Kerang Hijau (Perna viridis)

\begin{tabular}{clccc}
\hline No & $\begin{array}{c}\text { Peran } \\
\text { Kelompok } \\
\text { Nelayan }\end{array}$ & Skor & $\begin{array}{c}\text { Jumlah } \\
\text { Responden }\end{array}$ & $\begin{array}{c}\text { Prosentase } \\
(\%)\end{array}$ \\
\hline 1 & $\begin{array}{l}\text { Sangat } \\
\text { Berperan }\end{array}$ & 5 & 3 & 8,57 \\
\hline 2 & Berperan & 4 & 2 & 5,73 \\
\hline 3 & Cukup Berperan & 3 & 18 & 51,42 \\
\hline 4 & $\begin{array}{l}\text { Tidak Terlalu } \\
\text { Berperan }\end{array}$ & 2 & 12 & 34,28 \\
\hline 5 & Tidak Berperan & 1 & 0 & 0 \\
\hline & \multicolumn{1}{c}{ Total } & & 35 & 100 \\
\hline
\end{tabular}

Sumber: Hasil Penelitian (2017)

\section{Lembaga Pendidikan Tinggi}

Lembaga pendidikan Tinggi yang ada di wilayah Kota Tegal termasuk Fakultas Perikanan dan Ilmu Kelautan Universitas Pancasakti Tegal memiliki peran untuk mengembangkan bantuan teknis dan teknologi dalam pengelolaan sumberdaya alam dalam hal ini pengembangan kegiatan budidaya kerang hijau. Lembaga pendidikan tinggi tersebut selalu memberikan pengetahuan tentang budidaya kerang hijau dan memonitoring dalam pengembangan kegiatan budidaya, juga memberikan kurikulum khusus yang disebut muatan berbasis wirausaha yang mengajarkan tentang teknik budidaya kerang hijau (Perna viridis) dan psca panen. 
Tabel 3. Peran Pendidikan Tinggi dalam Kegiatan Budidaya Kerang $\mathrm{Hjau}$ (Perna viridis)

\begin{tabular}{ccccc}
\hline No & $\begin{array}{c}\text { Peran } \\
\text { Pendidikan } \\
\text { Tinggi }\end{array}$ & Skor & $\begin{array}{c}\text { Jumlah } \\
\text { Responden }\end{array}$ & $\begin{array}{c}\text { Prosentase } \\
(\%)\end{array}$ \\
\hline 1 & $\begin{array}{c}\text { Sangat } \\
\text { Berperan }\end{array}$ & 5 & 3 & 8,57 \\
\hline 2 & Berperan & 4 & 2 & 5,73 \\
\hline 3 & $\begin{array}{c}\text { Cukup } \\
\text { Berperan }\end{array}$ & 3 & 18 & 51,42 \\
\hline 4 & $\begin{array}{c}\text { Tidak } \\
\text { Terlalu } \\
\text { Berperan }\end{array}$ & 2 & 12 & 34,28 \\
\hline 5 & $\begin{array}{c}\text { Tidak } \\
\text { Berperan }\end{array}$ & 1 & 0 & 0 \\
\hline & Total & 35 & 100 \\
\hline
\end{tabular}

Sumber : Hasil Penelitian (2017)

Dalam Tabel 3. terdapat 12 responden memilih Berperan dan sebanyak 18 responden memilih Cukup Berperan. Berdasarkan hasil analisis korelasi Product Moment didapat hasil 0,368 (pernyataan 4), jika dibandingkan dengan angka kritik tabel korelasi nilai -r maka pernyataan ini memili-ki validitas konstruk, artinya memiliki hu-bungan korelasi dengan pernyataan yang lain.

\section{Tingkat Pengetahuan Dan Respon} Kelompok Nelayan

\section{Pengetahuan Kelompok Nelayan Tentang Budidaya Kerang Hijau (Perna viridis)}

Proses pengembangan potensi budidaya kerang hijau (Perna viridis) di Kelompok Nelayan "Gulamah” Kelurahan Panggung Kecamatan Tegal Timur Kota Tegalberlangsung selama 3 tahun dan selama ini masyarakat terutama nelayan telah mengetahui bagaimana cara budidaya kerang hijau dan metode yang digunakan dalam kegiatan budidaya, serta peran swasta yang senantiasa selalu memberikan penyuluhan atau juga pelatihan teknik budidaya (Asbar,2007).

Pengetahuan kelompok nelayan dalam budidaya kerang hijau (Perna viridis) tersaji pada Tabel 4.

Tabel 4. Pengetahuan kelompok nelayan dalam Kegiatan Budidaya Kerang Hijau (Perna viridis)

\begin{tabular}{clccc}
\hline No & $\begin{array}{c}\text { Peran } \\
\text { Nelayan }\end{array}$ & Skor & $\begin{array}{c}\text { Jumlah } \\
\text { Responden }\end{array}$ & $\begin{array}{c}\text { Prosentase } \\
\%\end{array}$ \\
\hline 1 & $\begin{array}{l}\text { Sangat } \\
\text { Berperan }\end{array}$ & 5 & 19 & 54,28 \\
\hline 2 & Berperan & 4 & 13 & 37,14 \\
\hline 3 & $\begin{array}{l}\text { Cukup } \\
\text { Berperan }\end{array}$ & 3 & 3 & 8,58 \\
\hline 4 & $\begin{array}{l}\text { Tidak } \\
\text { Terlalu } \\
\text { Berperan }\end{array}$ & 2 & 0 & 0 \\
\hline 5 & $\begin{array}{l}\text { Tidak } \\
\text { Berperan }\end{array}$ & 1 & 0 & 0 \\
\hline & Total & 35 & 100
\end{tabular}

Sumber : Hasil Penelitian (2017)

Pada Tabel 5 dapat dilihat ada 19 responden memilih jawaban Sangat Berperan $(54,28 \%)$ dan 13 responden memilih jawaban Berperan. Berdasarkan hasil anali-sis korelasi Product Moment didapat hasil 0,395 (pernyataan 5), jika dibandingkan dengan angka kritik tabel korelasi nilai -r maka pernyataan ini tidak memiliki validitas konstruk, artinya tidak memiliki hubungan korelasi dengan pernyataan yang lain.

Dari hasil uraian di atas, nelayan memiliki peran yang cukup baik dalam 
kegiatan pengembangan budidaya kerang hijau Mereka terlibat langsung dalam kegiatan budidaya kerang hijau tanpa ada paksaan dan bayaran dari pihak manapun, karena mereka berpendapat disamping melakukan kegiatan penangkapan ikan juga melakukan kegiatan budidaya kerang hijau sebagai pendapatan alternatif seorang nelayan untuk meningkatkan kesejahteraan nelayan (Noor, A. 2009).

Peran kelompok nelayan ini merupakan salah satu faktor penting dalam keberhasilan usaha budidaya perikanan adalah pemilihan lokasi yang tepat untuk budidaya kerang hijau (Ghufran M, 2004). Lokasi ini dapat ditentukan dari berbagai segi, seperti: aspek ekonomisosial dan biologi serta aspek teknis budidaya. Ketiganya harus saling mendukung guna keberhasilan budidaya kerang hijau pada kelompok nelayan "Gulamah" Kelurahan Panggung Kecamatan Tegal Timur Kota Tegal.

Usaha budidaya kerang hijau di Pesisir Kota Tegal baru dirintis sejak tahun 2015. Untuk pengembangan budidaya kerang hijau yang dilakukan kelompok nelayan dengan metode floating box cendrung lebihmudah daripada budidaya ikan dan tidak memerlukan perlakuan intensif setiap hari. Hal ini membuat masyarakat kelompok nelayan "Gulamah" tertarik mengembangkannya.

Matos, et al (2006), menyatakan kegiatan budidaya kerang hijau biasanya menggunakan 4 metode yaitu: metodatan cap (post method), jaring apung (raft method), rakit tancap/rak (rack method) dan tali rentang (long line method). Pada kelompok nelayan "Gulamah" lebih memilih dengan metode floating box dibandingkan dengan metode yang ada. Pemilihan metode ini berdasarkan pada kualitas dan daya dukung lingkungan perairan yang dimiliki (Neori, et al, 2000).

Pada perairan Kota Tegal lebih mudah menggunakan metode floating box, hal ini karena kedalaman perairan yang mendukung terutama dipesisir Kota Tegal.

\section{KESIMPULAN DAN SARAN}

\section{Kesimpulan}

Berdasarkan hasil dan pembahasan, maka dapat ditarik beberapa kesimpulan sebagi berikut :

1. Hasil penelitian menunjukkan bahwa pemerintah Kota cukup berperan dalam proses pengembangan budidaya kerang hijau pada kelompok nelayan "Gulamah" Kelurahan Panggung Kecamatan Tegal Timur 
Kota Tegal;

2. Pengembangan budidaya kerang hijau memiliki peran yang sangat besar pada kelompok nelayan "gulamah" yang ada di Wilayah Pesisir Kota Tegal;

3. Lembaga pendidikan Tinggi di wilayah pesisir Kota Tegal memiliki cukup peran dalam pengembangan budidaya kerang hijau (Perna viridis);

4. Kelompok nelayan "gulamah" merupakan pihak yang sangat berperan dalam upaya pengembangan budidaya kerang hijau (Perna viridis).

\section{Saran}

Berdasarkan hasil penelitian yang dilakukan, dapat disarankan bahwa, diharapkan hasil penelitian ini dapat mendorong pemerintah serta instansi terkait untuk lebih berperan serta dalam pengembangan budidaya kerang hijau (Perna viridis) di Kawasan pesisir Kota Tegal khususnya di Kelurahan Panggung Kecamatan Tegal Timur Kota Tegal.

\section{DAFTAR PUSTAKA}

Anonimous, 2005. Departemen Kelautan dan Perikanan. www.dkp.com. Tanggal akses 13 Maret-2017

Asbar, 2007. Optimalisasi Pemanfaatan Kawasan Pesisir untuk Pengembangan Budidaya
Tambak Berkelanjutan di Kabupaten Sinjai, Sulawesi Selatan. Disertasi Program Pascasarjana IPB (tidak dipublikasikan).

Badan Pusat Statistik Kota Tegal. 2016. Kota Tegal dalam Angka 2016.

Gang, C. L. Shaojing, Y. Shengyum. 1998. Estimation of Carrying Capacity for Mariculture Development in Xiamen. In The Regional Workshop on Partnership in the Aplication of Integrated Coastal Management, Chonburi, Thailand, pp. $81-90$.

Ghufran, M, 2004. Budidaya Ikan Laut di Keramba Jaring Apung, Rineka Cipta, Jakarta.

Matos, J.S. Costa. A. Rodrigues, R. Pereira, and I.S. Pinto. 2006. Experimental Integrated Aquaculture of Fish and Red Seaweed in Northern Portugal. Aquaculture. (252): 31-42.

Neori, A., M. Shpingel, and D.Ben Ezra. 2000. A Sustainable Integrated System for Culture for Fish,Sseaweed and Abalone. Aquaculture (186): 279-291.

Noor, A. 2009. Model Pengelolaan Kualitas Lingkungan Berbasis Daya Dukung (Carryng Capacity) Perairan Teluk Bagi Pengembangan Budidaya Karamba Jaring Apung Ikan Kerapu. (Studi Kasus di Teluk Tamiang, Kabupaten Kota Baru, Provinsi Kalimantan Selatan) Disertasi Sekolah Pascasarjana Institut Pertanian Bogor (Tidak Dipublikasikan). Bogor.

PERDA Provinsi Jawa Tengah No 04 Tahun 2014 tentang Rencana Zonase wilayah pesisir dan pulau pulau kecil. 
Rais, J., B. Sulistiyo, S. Diamar, T. Gunawan, M. Samampouw, T.A. Soeprapto, I. Suhardi. A. Karsidi, dan S. Widodo. 2004. Manata Ruang Laut Terpadu. PT. Pradnya Paramita, Jakarta.

Sugiyono, 2006. Metode Penelitian Administrasi ALFABETA. Bandung. 